\title{
Corrigendum: TCTEX1D2 mutations underlie Jeune asphyxiating thoracic dystrophy with impaired retrograde intraflagellar transport
}

Miriam Schmidts, Yuqing Hou, Claudio R. Cortés, Dorus A. Mans, Celine Huber, Karsten Boldt, Mitali Patel, Jeroen van Reeuwijk, Jean-Marc Plaza, Sylvia E.C. van Beersum, Zhi Min Yap, Stef J.F. Letteboer, S. Paige Taylor, Warren Herridge, Colin A. Johnson, Peter J. Scambler, Marius Ueffing, Hulya Kayserili, Deborah Krakow, Stephen M. King, UK10K, Philip L. Beales, Lihadh AI-Gazali, Carol Wicking, Valerie Cormier-Daire, Ronald Roepman, Hannah M. Mitchison \& George B. Witman

Nature Communications 6:7074 doi:10.1038/ncomms8074 (2015); Published 05 June 2015; Updated 29 Mar 2016

The financial support for this article was not fully acknowledged. The Acknowledgements should have included the following:

PLB was supported by the National Institute for Health Research Biomedical Research Centre at Great Ormond Street Hospital for Children NHS Foundation Trust and University College London.

(c) (i) This work is licensed under a Creative Commons Attribution 4.0 International License. The images or other third party material in this article are included in the article's Creative Commons license, unless indicated otherwise in the credit line; if the material is not included under the Creative Commons license, users will need to obtain permission from the license holder to reproduce the material. To view a copy of this license, visit http://creativecommons.org/licenses/by/4.0/ 